\title{
Needs Assessment for an Information System to Support a TB Control Program in Indonesia
}

\author{
Noor Alis Setiyadi i, ${ }^{1,}$ and Maryani Setyowati ${ }^{2}$ \\ ${ }^{1}$ Departement of Public Health, Faculty of Health Science, Universitas Muhammadiyah Surakarta, \\ Indonesia \\ ${ }^{2}$ Faculty of Health, Universitas Dian Nuswantoro Semarang, Indonesia \\ ORCID \\ Noor Alis Setiyadi: https://orcid.org/0000-0002-9780-4106
}

Corresponding Author: Noor Alis

Setiyadi; email:

nooralissetiyadi.2019@gmail.com

Published: 7 February 2022

Publishing services provided by

Knowledge E

(c) Noor Alis Setiyadi, and

Maryani Setyowati . This article is

distributed under the terms of

the Creative Commons

Attribution License, which

permits unrestricted use and

redistribution provided that the

original author and source are

credited.

Selection and Peer-review under the responsibility of the IVCN Conference Committee.
Abstract. Tuberculosis (TB) is still a burden in Indonesia, including in Sukoharjo Regency. The wide gap between the estimated TB cases and those found, and the number of fluctuating cases since 2013 are problems for the Sukoharjo Health Office. Various programs have been created and carried out but Sukoharjo is still ranked low in TB case identification. The aim of this study was to map the information requirements to support the the identification of TB cases by the district health office. This research was a needs assessment, based on the system development life cycle (SDLC) approach. Qualitative data were obtained from in-depth interviews, including with the head of the TB program in the Puskesmas public health center, a TB program supervisor, a head of communicable disease control, a head of disease control, and a head of health systems in Sukoharjo, Central Java, Indonesia. Several programs were identified such as knock-on programs, screening of cross-sectorial TB suspects including Aisyiah TB-HIV care, and strengthening of PISPK (Healthy Indonesia Program With a Family Approach). Strengthening of TB health volunteers was still being carried out, but the achievement of TB screening was still low. Informants were still looking for ways to improve screening for suspected TB. The health agency had not yet developed a decision support system that could be used to help plan TB screening programs, but the health office wanted one to be developed. An information system is needed to help make evidence-based programs to find TB cases.

Keywords: needs assessment, system, TB control, Indonesia

\section{Introduction}

TB case reports in Indonesia since 2014 provided a signal that TB had been expected to increase and account for $10 \%$ of TB cases in the world[1]. Another word, annual TB incidence in Indonesia reach 1,020,000 cases [2]. In national strategic plan 2016-2020 stated that there are sixth issues regarding of TB elimination in Indonesia by 2030 , namely strengthening leadership in the district level management, improving access to the quality services, control of risk factors, enhancing TB partnership through the coordination forum, Engaging community in TB control, and health system strengthening

\section{G OPEN ACCESS}

[2]. 
Related with the health system, the regulation of National Health Information System in Indonesia enactmented since 2014 lead to the electronic system development of health. Puskesmas (primary health care) as the first level of health service had been a strategic role to improve the health status under its region. [3].A health system developed is to provide a high quality of data and suitable in decision making for the organization[3].

In Indonesia, a information system run for TB program is SITT as a national standard in recording and reporting of TB, although in Ramadhani's research revealed that the implementation contained several deficiencies such as SITT data errors, and were unstable[4]. From the output side, the information presented is TB prevalence, conversion results, recovery, success rate, estimated number of suspects examined, CDR, all case data, suspect coverage data examined, CDR compared to target and cross-test results, and meeting of the head of the puskesmas, and program managers routinely. [4]. However, the design of the SITT application required to be reviewed. Another researcher also recommended that the SITT should be assessed.[5].

The case finding rate in Indonesia since 2016, 2017 and 2018 only reached 35\%, so that a breakthrough or innovation is needed in increasing TB case finding. On the other hand, there are still 2.2\% TB deaths in 2018 and MDR-TB findings in 2 cases in 2018. [6]

Sukoharjo regency is a district located in Central Java Indonesia which is reported having a wide gap between the number of estimation TB and number of TB case found. The CDR (crude detection rate) reported had been arround 35\% within 3 years (2016-2017-2018). So, system needs analysis is needed as to what can be used as evidence-based for decision making on TB case finding programs in Sukoharjo.

It aimed to map the information requirements of levels under a district health office area for different levels of management in term of data input, output of information, and it contents to support a TB program particulartly in TB suspects found and monitoring.

\section{Methods}

The study was a qualitative descritive with narrative approach. The data were collected in Sukoharjo, central java which have a low of case detection rate of TB. The subjects were a head of disease control, a head of section in infectious disease control, vice of supervisor in TB programmer, and section of data and information on distict health office. The participants represented as the key informant on tuberculosis program, data and control. 
TABLE 1: General Information of the Participants

\begin{tabular}{l|l|l|l|} 
N & Gender & Position & Education \\
Participant 1 & Male & Head of P2 & Master \\
\hline Participant 2 & Male & Head of P2P & Diploma \\
Participant 3 & Male & Vice of TB supervisor & Diploma \\
Participant 4 & Male & Vice of data and information Diploma
\end{tabular}

\subsection{Data collection}

Ethical approval was obtained from board of health research and development, ministry of health, Indonesia by no: LB.02.012/KE.222/2019 on 19 June, 2019. The data were collected from july to september 2019 in that study location. A semistructured interview technique was used to collect the information of the system related to TB control system and TB suspect investigation. The interview guideline used to assess the need of a system appropriated by users[7, 8]. The authors used this instrument as an interview guideline in qualitative study approach to understand more about the finding in the previous study. All the interviews were recorded and transcribed to data analysis.

\subsection{Data analysis}

The transcript was initially written in Indonesia language, then the subsequently translated into English. After the researcher team tranlated the transcripts into english, the data was analyzed with Nvivo software. The researcher developed initial coding and sub coding of similiar data base on it. Lastly, thematic analysis was carried out to identify and developed the arising themes.

\section{Results}

\subsection{Tuberculosis data management}

The TB data in regency health office level is organized by a data officer supported by TB programmer, as the statement, " regency office was obtaned the data from TB officer in puskesmas level, so the data officer analized supporting by TB programmer in district level. The all data is organized by that data officer and TB programmer". (P1)" 


\subsection{The form of data input used}

The TB data format that being reference to the Health Office of Sukoharjo District refers to the Indonesian Ministry of Health, as stated "for TB data, we in addition to using a standard format, we use an application or SITT that has been developed, it only refers to the Ministry of Health". (P2).

\subsection{Suspect investigation and case finding system approach}

The Sukoharjo District Health Office made active and passive discoveries, as stated, "active or passive discovery, waiting for the patient to come, we will also conduct contact check, such as BTA (+) and TB, the child will visit home". (P1)

The number of case finding reported was obtained by collaboration with other organization, as stated, " we collabore with Aisyiah NGO for case finding and also orgazise with heatlh village volunteers who visit to their home actively". (P2)

If the the number of case finding obtained was low, the TB officers visited to villages for public relation approach, as stated, "the public relation approaches to villages which is the risk factor area undertaken to make people aware of TB transmission". (P1)

\subsection{The current system used to TB control}

The existing system cannot be used to monitor TB treatment, as stated, "indeed for this system, in addition to wifi-TB, it is also easy to use "PCare" applications but "PCare" is still very limited, so it is only a derivative, not yet reflecting, so only it is made in general, so it cannot be used to monitor for treatment TB". (P2)

The difference between SITT and wifi-TB information systems is in the graphic displayed where only SITT can displays the graph. Another reportings provided by SITT is the tables, as stated below.

\subsection{Sistem decision support system (DSS) to manage TB cases}

The policy support system that already exists in the Sukoharjo District Health Office Work Area is SITT and all health services in the puskesmas work area are under the auspices of the puskesmas, as stated, "we have been SITT all this time". (P1) and "all health services in there in the area are puskesmas, yes under his control, doctors practice clinics unless referral”. (P2) 


\subsection{Expected System}

The expected system by the Health Office of Sukoharjo District must be able to display treatment and cure data. The head of P2P department supports the development of software to facilitate decision making and the existing system is expected not to overburden officers like the entries again, as stated. "so how much is the target and then how much is healed then how much is recovery". "If from the indicator it is actually sufficient to be seen from the first indicator, if possible other variables we might not be able to get yet". (P1) and "We are very supportive when facilitating policy makers in making decisions ". "But if then there is an application that is for policy holders what does it mean is simpler based on management needs". (P2)

It is necessary to add colour to the map to be more informative by classifying low, medium and high risks. In the high risk classification, it is necessary to note program recommendations that must be carried out.

"If the easier area-based display will really help us color, so that we already know which areas are at risk if the term problematic colors can be written later such as high risk, or maybe high risk. High risk, moderate risk. It might be can be added". (P1)

Collaboration between agencies is needed to improve the degree of public health. Collaboration that can be carried out in this program for example cooperation with social services in helping TB patients who are poor.

"With inter-related programs such as TB patients with poor indicators, the data will be given to the social service, because the term is assisted by the poor." (P2)

A deputy TB supervisor expects each coordinate to describe the number of TB patients. When highlighted on the map location, it is expected to display data names, addresses, telephone numbers, KK numbers, and KTP numbers. This is consistent with the statement of the TB suvervisor representative below.

"Basically, the name of the telephone number is the same as the number of the ID card later in the folder, when it is highlighted, the name of the telephone number directly appears, it might also be possible to show up a house photo, a side photo or a front photo, he said, a photo of the house is necessary. maybe if you click on the point immediately appears graphical info and then there is a picture of the house and then there is a picture of the environment that is needed He is that if the operator image in the field using Android he shares the location with the person's photo uploaded to the server." (P4) 


\subsection{The obstacle of system run}

Not all of health service facilities operate the system, Sukoharjo District Health Office has approached several potential clinics. However, private practice does not yet provide DOTS services because there are still doctors who do not understand DOTS services.Example statement

"Not all of health service facilities from the private sector want to run the system, especially for clinics and private doctors". (P1)

\subsection{The strenght belong to health district office to deliver the sys- tem}

There have been several hospitals that have proposed cooperation, as stated below.

P2: There has been progress. They have started several hospitals, including the new hospital, which has proposed cooperation from us.

In addition to hospitals, clinics and doctor's practices have also worked together, as stated below.

P2: The entry of the doctor, so that's we, 14 are clinics with doctors.

\section{Discussion}

Need assessment, which is the process of gathering information about the desires of an organization that is conveyed or desired[8]. Health needs assessment is a systematic method for health problems in a population that is approved to have an impact on improving health and reducing inequality [9].

Need assessments that have been carried out at the level of TB program decision making at the levels of health department work area, namely the district health office level and the district / puskesmas level. This refers to the statement thatThe disease prevention section (P2) at the district health office level requires a system that makes it easy for health offices to make decisions regarding TB programs including crosssectoral programs. A study in the Philippines explains that the provision of traceable information at all levels is a key in strengthening the health system and improving the quality of health services[10].

TB data is inputted and reported using national standards which are also used in SITT because it is in accordance with national guidelines. The results of other research 
revealed that the desired information system is one that can produce quality data and information to support the tuberculosis surveillance system[11]

Needs assessment is the process of gathering information about the needs of the organization both express and implied; the process to ensure that the assessment is carried out about the availability of time and resources[8, 9].

A limited set of processes related to using data for decision making at the district level [12].Also, decision making on epidemiological topics; Research focusing on health management information systems develops tools to improve the management and use of health information[12].

Disease surveillance is a continuous examination of all aspects of disease occurrence and spread to detect changes in disease trends or distribution to initiate control measures [13]. In TB, which includes monitoring people who come into contact with TB patients, for that screening program, proper management is an opportunity for prevention and discovery of TB cases[14].

The main objectives of the HIS need assessment are to overcome the problem of developing information systems with the specific goal of determining the adequacy and relevance of HIS at all of levels of the health service system, evaluating the extent to which the health information system supports management of services and activities, and identifying weaknesses of the information system and solve it[13].

The discovery of TB suspects, despite being actively and passively carried out in collaboration with NGOs of Aisyiah, it is still not felt to be significant. This was done because of collaboration with NGOs, encouraging the community and related sectors [12].For this reason, the information provided can be used as a basis for finding the suspects. This is because information needs are dynamic and include program information [10].

\section{Limitations}

This study only explored the need of a system help to decide a program regarding the TB program in a regency.

\section{Conclusions}

Related to find the TB suspects in a regency was needed a system to make a decision easier to find the evidence to improve the number of these suspects. 


\section{Funding information}

This research was funded by grant of riset IPTEK kesehatan, Ministry of Health, Indonesia

\section{References}

[1] Burkot C. New Indonesia data behind rise in global TB cases. 2015;133.

[2] Ministry of Health, Indonesia. Current status of integrated community based TB service delivery and the Global Fund work plan to find missing TB cases. Ministry of Heatlh, Indonesia.

[3] Afrizal SH, Handayani PW, Hidayanto AN, et al. Barriers and challenges to Primary Health Care Information System (PHCIS) adoption from health management perspective: A qualitative study. Informatics Med Unlocked. 2019:100198.

[4] Ramadhani NR. Evaluasi sistem informasi tuberkulosis (SITT) di rumah sakit paru respira yogyakarta dan dinas kesehatan provinsi daerah istimewa yogyakarta dengan metode technology acceptance model (TAM). Universitas Muhammadiyah Surakarta; 2018.

[5] Firmani N. Evaluasi efektifitas penerapan sistem informasi tuberkulosis terpadu (SITT) dengan pendekatan hot fit model di puskesmas se-kota semarang. Universitas Diponegoro, Indonesia; 2015.

[6] Dinkes. Profil kesehatan kabupaten sukoharjo. Sukoharjo; 2018. DOI: 10.1017/СBO9781107415324.004

[7] Assessment CN. Comprehensive needs assessment materials adapted from planning and conducting needs assessments: A practical guide. Archived Information. 2001:1-25.

[8] Barbazette J. What is needs assessment?? Train Needs Assess. 2006:3-14.

[9] Quality improvement \& innovation partnership. Needs assessment resource guide. Adv Improv Prim Healthc Ontario. 2009. DOI: 10.1136/bmj.316.7142.1448

[10] Kapadia-Kundu N, Sullivan TM, Safi B, et al. Understanding health information needs and gaps in the health care system in Uttar Pradesh, India. Journal of health communication,. 2012;17:30-45.

[11] Setiyadi NA, Prasetyo SB. Improving the quality of education to face the impact of technology. Purwokerto: Universitas Muhammadiyah Purwokerto; 2013. Development of Surv-TB (Tuberculosis Surveillance Webgis); pp. 343-346. 
[12] Wickremasinghe D, Hashmi IE, Schellenberg J, et al. District decision-making for health in low-income settings: A systematic literature review. Health policy and planning. 2016;31:12-24.

[13] World Health Organization. Health information systems development and strengthening: Guidance on needs assessment for national health information systems development.

[14] Lestari T, Graham S, Boogard C Van Den, et al. Bridging the knowledge-practice gap in tuberculosis contact management in a high-burden setting: A mixed-methods protocol for a multicenter health system strengthening study. 2019:1-15. 